\title{
ARNI, LBBB, COVID-19 and various other topics
}

In this issue of Anatolian Journal of Cardiology, Polednik et al. from Czech Republic reviews the relationships between stroke and coronary artery disease. They suggest screening for that the common risk factors.

Aslanger et al. from Turkey and USA discuss the origins, evidence-base and limitations of the ST-elevation myocardial infarction (STEMI)/non-STEMI paradigm and call for a new paradigm shift in cardiology by suggesting the use of new terminologies of occlusion $\mathrm{MI}(\mathrm{OMI}) /$ non-OMI. This proposition could be of great interest to the cardiologists.

Evaluating the effect of the necessary -discontinuation of Sacubitril-Valsartan-due to financial shortage or adverse effects-and shifting to an angiotensin-converting enzyme inhibitor or angiotensin receptor blocker in the patients with heart failure with reduced ejection fraction is the aim of the study from Egypt conducted by Amin and Alaarag. This study documents their real-life experience with this situation.

It is unclear whether left bundle branch block (LBBB) is a marker for more clinically advanced cardiac disease or an independent causative factor for increased mortality and the development of heart failure. Ashraf et al. from USA investigated the natural history of isolated LBBB without any associated structural heart disease to characterize its clinical significance. This study will significantly contribute to this field.

Distal radial artery access or trans-snuff box access (TSA) is a novel, safe, and feasible technique for coronary artery interventions. However, achieving adequate hemostasis remains challenging. Therefore, the purpose of the study from Iran by Roghani-Dehkordi et al. was to compare two methods of hemostasis, containing both manual and mechanical compression approaches, in the patients undergoing coronary angiography via TSA.

The full effects of the triple combination therapy containing hydroxychloroquine, antiviral, and antibiotic drugs on ECG parameters in mild to moderately symptomatic patients suffering from COVID-19 are not fully understood; therefore, in this study, Uğurlu Ilgın et al. from Turkey explored the changes in ECG parameters after administering the triple combination therapy in the patients with mild to moderately severe COVID-19. The authors advise keeping an eye on the ECG parameters while administering this triple therapy.

Although patients with prosthetic heart valves are at an increased risk of clinically overt cerebrovascular events, evidence for the risk of silent cerebral infarction (SCI) is scarce. Serum neuron-specific enolase (NSE) is suggested to be a valid biomarker that allows the quantification of the degree of neuronal injury. Özyüncü et al. from Turkey assessed whether elevated NSE is a marker of recent $\mathrm{SCl}$ in the patients with a prosthetic mitral valve. The answer may lie in inadequate anticoagulation.

Investigating major and minor bleeding event rates, sites, and management of the patients with nonvalvular atrial fibrillation treated with direct oral anticoagulants was the aim of this prospective study with one-year follow-up of real-life data, as a part of the NOAC TURK study, carried out by Gedikli et al. from Turkey. This is a meticulously conducted study that offers new insights.

In addition, informative case reports and e-page originals are also included.

I hope this issue of our journal will be of interest to our readers.

\section{Prof. Dr. Çetin Erol \\ Editor-in-Chief \\ Ankara-Turkey}

Address for Correspondence: Prof. Dr. Çetin Erol, Ankara Üniversitesi Tıp Fakültesi, İbn-i Sina Hastanesi, Kardiyoloji Anabilim Dalı, Ankara, Türkiye

Phone: +90 3123103333 /27 79 E-mail: ctnerol@yahoo.com

(C) Copyright 2021 by Turkish Society of Cardiology - Available online at www.anatoljcardiol.com

DOI:10.5152/AnatolJCardiol.2021.3 